\title{
The Determinants of Publication Rates of Faculty Members at a Canadian University
}

\author{
VAUGHAN A. DICKSON*
}

\begin{abstract}
This paper examines the determinants of inter-individual differences in publication rates for a sample of faculty members in a Canadian university. A simple model of publication output is presented and tested with an ordinary least squares regression. Among the conclusions are that academic rank, degree qualifications, academic discipline and the number of years since receipt of first degree significantly influence publication rates.
\end{abstract}

\section{RÉSUMÉ}

Cet article examine les déterminants inter-individuels des taux de publication d'un échantillon de professeurs appartenant à une université canadienne. On présente un modèle simple, où les publications sont traitées en "output", et on le vérifie au moyen de techniques de régression. Parmi les conclusions, on en trouve que le rang et les qualifications professionelles, aussi bien que la discipline et le temps parcouru dès l'obtention du premier titre académique, ont une influence significative sur le taux de publication.

An important function of universities is producing knowledge. The published research done within universities is one indicator of this production and the contribution of universities to society. Given this, an important question is what determines the amount of publishing done by faculty? This is the question addressed in this paper. A simple model is developed and tested which relates individual characteristics of faculty at the University of New Brunswick (UNB) to their published research over a four year period. In the next two sections the

* Department of Economics, University of New Brunswick. 
sample, the measure of publication output, and the model are introduced. In the section following these, the results of a least squares regression are reported. A discussion of the results, policy implications, and future research problems is contained in the last section.

\section{DEFINING THE SAMPLE AND MEASURING PUBLICATION OUTPUT}

The University of New Brunswick (1982) published a document entitled Faculty Publications List, University of New Brunswick (FPL). It lists publications of faculty for the calendar years 1978-1981 inclusive. This document was used to solve the problems of defining the sample and measuring the published output of persons in the sample. Each problem is considered in turn.

\section{Sample Definition}

The sample was defined to include all those listed in the FPL in the Arts, Science, Administration and Engineering faculties subject to the following additions and deletions. First a person must have been employed at UNB for the full period 1978-1981 to be in the sample. Secondly people who did not publish during this period are not in the FPL but are in the sample. These people, together with those employed for the four year period, were identified by inspection of the faculty listings in two editions of the Undergraduate Calendar published by UNB (1977, 1981). Lastly persons on sabbatical in the academic year 1981-82 were omitted. This is because the FPL was compiled in the spring of 1982 and there is some indication that the responses of sabbaticants were incomplete. These additions and deletions resulted in a sample of 245 persons.

\section{Measuring Publication Output}

The publication measure was constructed from the FPL's category A which lists (p. 4), "research and scholarly publication including articles, papers, books, reviews, etc., of a scholarly nature originating in research or independent inquiry". The publication measure employed, called PUB, was the number of articles authored or co-authored, plus the number of books edited or co-edited, plus the number of books, weighted by 5 , authored or co-authored. Book reviews were not included in PUB because of their uncertain research nature.

PUB is obviously less than a perfect proxy for published research output. Among its shortcomings are an ad hoc weighting of book output, and a failure to account for differences among articles in quality. (However any bias that does occur because of ad hoc weighting of book output is likely small since book output is 18 while other entries total 870 . In fact regressions tried with a weighting of 1 and 5 for books were almost identical).

\section{THE MODEL}

To explain individual differences in PUB an ordinary least squares regression was used in which PUB was regressed against variables representing academic rank, 
degree qualifications, academic discipline, and number of years since receipt of first degree (YSFD). All variables, except PUB and YSFD, are in UNB's Undergraduate Calendar for the academic year 1977-78. YSFD values were provided in a blind form by UNB's personnel office. The mnemonic, definition and explanation for each variable follows.

ASSIST, ASSOC - These are respectively dummy variables designating assistant and associate professors. If the rank held during the academic year 1977-78 was assistant professor ASSIST $=1$, otherwise ASSIST $=0$. ASSOC is defined analogously for associate professors. The hypothesis is that academic ranks reflect research ability. The coefficients on ASSIST and ASSOC should be negative since assistants and associates should produce less than full professors, ceteris paribus. The academic year 1977-78, rather than 1981-82, was used to fix academic rank to avoid any simultaneous equations bias that can arise since rank is likely a function of past publications. A variable closely related to academic rank that would be interesting to test is tenure status. Unfortunately complete data on tenure status were unavailable.

PHD - This is a dummy variable equal to 1 for doctorates and zero otherwise. The hypothesis is that the doctorate confers research skill which results in more publications, ceteris paribus. Therefore the coefficient on PHD is expected to be positive.

BUS, SS, SCI, ENG - These are dummy variables representing respectively business administration, the social sciences, the natural sciences and engineering. BUS equals 1 if a person is in business administration, and zero otherwise. The other variables are defined likewise. The omitted group is the humanities (HUM), who with the social sciences constitute the Arts Faculty. Since the omitted group is the humanities, the coefficient on each dummy measures that discipline's publication propensity against the humanities. These dummy variables are introduced since there may be differences among disciplines in the opportunity to publish. For example, Rushton and Meltzer (1979) provide data that indicate the number of publications in the sciences is greater than in the humanities and social sciences.

LYSFD, LYSFD·PROF - LYSFD measures the natural logarithm of years since first degree (YSFD) for each person. LYSFD·PROF is a slope dummy variable which equals LYSFD if a person is a full professor and zero otherwise. For LYSFD, the hypothesis is that much publication stems from ideas and methodologies developed early in one's career. As time passes these ideas are "mined out" or become obsolescent. Therefore the expected coefficient for LYSFD is negative.

The introduction of LYSFD PROF is done to account for differential incentives to publish across ranks. Assistant and associate professors, who wish to be promoted, should have a greater incentive to remain current so as to publish. Therefore the negative impact of LYSFD should be greater for full professors, and the coefficient on LYSFD.PROF is expected to be negative.

The natural logarithm of the YSFD variables was used since this transformation yielded slightly stronger t-statistics in the regressions performed. The use of 
the logarithmic transformation of YSFD (LYSFD) implies that the negative influence of YSFD on PUB is at first gradual but increases at an increasing rate with time. This is in contrast to the untransformed YSFD which implies a linear decline for PUB with respect to YSFD.

The model of faculty behavior implicitly summarized by the above variables is consistent with an economics model of constrained utility maximization for professors. In such a model professor i's utility depends positively on PUB. However, the utility level reached is constrained by the time available for research, and i's ability to convert research effort into PUB. The academic rank, degree qualifications, LYSFD and academic discipline variables represent i's ability to convert research effort into PUB. The differential impact of LYSFD across ranks occurs because the utility from an extra PUB differs across ranks.

\section{RESULTS}

First Table 1 is introduced to provide information about the sample and data. Table 1 gives summary statistics for some of the variables identified in the previous section. Inspection of Table 1 implies that publication rises with rank. A more complete analysis, however, requires the multiple regression equation that follows.

The regression equation that results from regressing PUB against the defined independent variables is presented in Table 2. The t-statistics show that, except for SS, all of the independent variables are significant at $\mathrm{p}<.058$ for a twotailed test.

Several comments concerning the regression are in order. First for the PHD and discipline dummy variables the results are unsurprising. Over the 4 year period a PHD can be expected to produce 2.21 more publications than a nonPHD. The different opportunities to publish among disciplines are shown since BUS, ENG, and SCI faculty can expect to produce respectively $2.61,2.48$ and 3.52 more publications than a humanities person. There is no significant difference in publishing between the social sciences and humanities.

The role played by the rank and 2 LYSFD variables is interesting. As expected the negative influence on PUB of LYSFD is stronger for full professors than for other ranks. For full professors the coefficient on LYSFD is $(-2.44-4.18)$ or -6.62 , whereas for all other ranks the coefficient is -2.44 .

The coefficients for ASSIST and ASSOC imply that assistant and associate professors produce 15.9 and 14.6 fewer publications than full professors. However these coefficients cannot be interpreted properly without simultaneously recognizing the negative influence of the 2 LYSFD variables, and that senior ranks typically have the largest LYSFD variables. (The simple correlation between LYSFD and PROF is .60 which is significant at $p<.05$.) Thus it may be that the superior publication performance of PROF is nullified by the greater impact of the LYSFD variables on full professors. 
Table 1

Summary Statistics Broken Down by Academic Rank

\begin{tabular}{|c|c|c|c|c|c|}
\hline & & ASSIST & ASSOC & PROF & ALL RANKS \\
\hline 1. & Faculty numbers & 62 & 93 & 90 & 245 \\
\hline 2 . & PUB per faculty member & 3.0 & 3.8 & 4.6 & 3.9 \\
\hline 3 . & Percent who publish & $66 \%$ & $72 \%$ & $74 \%$ & $71 \%$ \\
\hline 4. & Percent with PHD & $71 \%$ & $78 \%$ & $82 \%$ & $78 \%$ \\
\hline 5 & BUS faculty numbers & 4 & 2 & 4 & 10 \\
\hline 6 & SCI faculty members & 8 & 21 & 22 & 51 \\
\hline 7. & ENG faculty numbers & 10 & 18 & 20 & 48 \\
\hline 8 . & SS faculty numbers & 16 & 16 & 12 & 44 \\
\hline 9 . & HUM faculty numbers & 24 & 36 & 32 & 92 \\
\hline 10. & Mean YSFD & 12.5 & 17.5 & 24.5 & 18.8 \\
\hline
\end{tabular}




\section{Predicted Publication Rates}

To more fully investigate the opposing effects on PUB of more senior rank and, at the same time, larger LYSFD values the following exercise was performed. The value of PUB predicted by the regression and its 95 percent confidence interval was computed for PHD humanists with different academic rank and LYSFD values. For the regression this means setting $\mathrm{PHD}=1$, whereas BUS, ENG, SCI, and SS are all zero. To compute the predicted PUB for other faculties, e.g. SCI, is a simple matter of setting $\mathrm{SCI}=1$, multiplying by 3.52 and adding to the humanist numbers.

The results for the humanist PHD are in Table 3. The lowest YSFD numbers for each rank in Table 3 are based on the "ideal" of 4 years of graduate work before appointment to assistant professor, 5 years in rank before appointment to associate, and 6 years before appointment to full professor. (During this time 5 and 6 years were considered the "normal" time in rank for assistant and associate professors). The middle YSFD values for each rank are the sample means for that rank, and the largest YSFD numbers are the maxima observed in the sample for that rank.

Table 3 establishes that on average young full professors are most productive, that young associate and assistant professors are more productive than full professors of mean YSFD experience, and that older persons in all ranks produce PUB levels insignificantly different from zero.

\section{DISCUSSION}

This paper has examined the determinants of publication over a 4 year period at UNB. The more straightforward conclusions are that the doctorate increased publications, and that significant inter-faculty differences in the propensity to publish existed. The latter is taken to result from differences in publication opportunities across disciplines.

The roles played by the correlated rank and seniority (LYSFD) variables are less straightforward and more interesting from a policy perspective. The regression established that the higher academic ranks are more productive, ceteris paribus. At the same time the regression showed that seniority eroded productivity, and this erosion is greater for the higher ranks. Together these results raise issues related to the amount of published research that universities can expect in the future.

One issue concerns the large and significant LYSFD effect at the full professor level compared to the other ranks. This result may be especially important, in terms of the amount of future research done, as the ages and proportion of full professors in universities increase. At UNB, for example, as reported by Statistics Canada $(1978,1982)$, full professors were 26 percent of faculty in 1977-78 and 39 percent in 1981-82. Since the stronger LYSFD effect for full professors was attributed to lack of promotion incentives, this means that an incentive system at the full professor level may increase publishing. Another alternative would be 
Table 2

Regression Equation for the Determinants of Publishing (PUB)

Dependent
Variable

$\begin{array}{lcccccccccc}22.39 & -14.63 & -15.95 & 2.21 & 2.61 & 2.48 & 3.52 & .09 & -2.44 & -4.18 \\ & (3.82) & (2.23) & (2.50) & (3.26) & (1.90) & (3.28) & (4.82) & (.13) & (2.09) & (1.96)\end{array}$

$\mathrm{R}^{2}$ (corrected) $=.24, \mathrm{~F}=9.54, \mathrm{n}=245$

Note: Bracketed numbers are t-statistics. 
Table 3

Predicted PUB Value and 95 percent Confidence Interval for a PHD Humanist of Varying Rank and Experience

\begin{tabular}{|c|c|c|c|c|c|}
\hline YSFD & PROF & YSFD & ASSOC & YSFD & ASSIST \\
\hline 15 & $6.55 \pm 1.97$ & 9 & $4.50 \pm 1.89$ & 4 & $5.16+2.82$ \\
\hline 24.5 & $3.31+1.12$ & 17.5 & $2.88+1.09$ & 12.5 & $2.38+1.27$ \\
\hline 37 & $.65 \pm 1.89$ & 31 & $1.49 \pm 1.67$ & 30 & $.25 \pm 2.43$ \\
\hline
\end{tabular}


performance review with a potential for withholding salary increments. Of course the implementation of any system would require a thorough evaluation of its feasibility, money costs and research benefits.

Another issue concerns the extent to which these results are applicable at other universities. In particular would the negative LYSFD effect be as strong at very prestigious institutions? One conjecture is that peer pressure may be positively correlated with the prestige of the university, and greater peer pressure may act to reduce the negative impact of the LYSFD variables.

Lastly the predicted PUB values of Table 3 imply that, on average, the university receives less research from senior persons of all academic ranks. An interesting, and for now unanswered question, is to what extent does this mean that the university receives less value, rather than publication quantity, from senior personnel? One possibility is that senior people are more likely to concentrate less on quantity of research and more on other functions of the university. For example senior professors, because they are free from promotion pressure, may be more likely to shift from publishing per se towards teaching, administration, and more reflective but less frequent publication. To the extent this is a significant phenomenon, their contribution exceeds that implied by PUB.

This last argument suggests a final caveat. Namely that proposals to increase research can flounder if the only measure of research output is a numbers measure similar to PUB. If promotion and research reward committees concentrate too much on numbers, perhaps because for them also quality is difficult to ascertain, then there are incentives for faculty to emphasize quantity over quality.

\section{REFERENCES}

Rushton, J.P., \& Meltzer, S. Research productivity, university revenue, and scholarly impact of 31 Canadian universities. Canadian Journal of Higher Education, 1979, 9(3), 74-81.

Statistics Canada. Salaries of Full-Time Teaching Staff at Canadian Universities and Colleges. Ottawa: Statistics Canada, 1978.

Statistics Canada. Salaries and Salary Scales of Full-Time Teaching Staff at Canadian Universities. Ottawa: Statistics Canada, 1982.

University of New Brunswick. Undergraduate Calendar, University of New Brunswick. Fredericton, N.B.: University of New Brunswick, 1977, 198 to

University of New Brunswick. Faculty Publications List, University of New Brunswick. Fredericton, N.B.: University of New Brunswick, 1982. 